Wolbert G. C. Smidt

Universität Hamburg

\title{
DEUTSCHE BRIEFE VON ÄTHIOPIERN 1855-1869 AUS DEM UMKREIS DER PROTESTANTISCHEN MISSION ZUR REGIERUNGSZEIT VON TEWODROS II
}

\section{Zur Einführung: Der historische Hintergrund}

Die Machtergreifung des Königs der Könige Tewodros II. in Äthiopien 1855 wird zu Recht als Wendepunkt in der Entwicklung des modernen Äthiopien angesehen. Seine Herrschaft ist durch zahlreiche Reformversuche und teilweise regelrechte Umstürze - geprägt, die sowohl politische als auch theologische Traditionen des christlichen Reiches in Frage stellten. Das Reich erlebte eine seit langem ungekannte Zentralisierung weltlicher Macht und die Unterwerfung oder Integration bisher unabhängiger bzw. weitgehend autonomer lokaler Herrscher und Gouverneure. Von Anfang an war diese Politik auch von Europäern begleitet worden, als Beratern, Helfern und Kritikern. Der, vor allem indirekte, Einfluss dieser Europäer auf Tewodros II.' Politik ist nicht zu unterschätzen. Signifikant ist seine Bemerkung zu den kurz nach seiner Inthronisierung in das Land gekommenen protestantischen Missionaren aus der Schweiz, ${ }^{1}$ er sei nicht wie die Leute seines Volkes, sondern vielmehr wie ein Europäer. ${ }^{2}$ Auch in diesem Sinne beginnt mit seiner Herrschaft die Moderne in Äthiopien: Zwar haben zahlreiche Fürsten und Herrscher schon in den Jahrhunderten zuvor, seit dem europäischen Hochmittelalter,

${ }^{1}$ Vgl. Strebel, Barbara, «...den blinden Abessyniern die Augen aufzuthun», Chrischona-Pilgermissionare in Äthiopien (1856-1868), Geschichte eines gescheiterten Missionsprojektes, ms., Lizentiatsarbeit, Universität Zürich 1999; EAD., «Leben auf dem Missionsfeld. Crischona — Pilgermissionare in Äthiopien (1856-1868)», Aethiopica. International Journal of Ethiopian Studies 4, 2001, 121-157. — Zu dieser Mission siehe auch: FLAD, JohAnn MARTIN, 60 Jahre in der Mission unter den Falaschas in Abessinien, Gießen - Basel 1922; ArÉN, Gustav, Evangelical Pioneers in Ethiopia, Origins of the Evangelical Church Mekane Yesus, Uppsala - Addis Abeba 1978 (Studia Missionalia Upsaliensis, 32); CRummey, Donald, Priests and Politicians: Protestant and Catholic Missions in Orthodox Ethiopia, 1830-1868, Oxford 1972.

${ }^{2}$ «Do not believe I am an Abyssinian at heart; no, I am as one of you». Tewodros II. in einem Gespräch mit Kienzlen und Bender und anderen Missionaren, gemäß dem auf Englisch nachgedruckten Brief von J. J. Gottleib Kienzlen an Bischof Gobat (Einzelbogen), Gondar, May 4, 1859: Staatsarchiv Basel, PA 653, D3, Mappe 2.) No. 5 (G. Kienzler [Kienzlen!], Magdala 1858-1859). 
die Dienste einzelner Europäer in Anspruch genommen, doch seit der Vertreibung der Jesuiten 1632 hatte es keine permanente Europäer-Kolonie mehr gegeben, und keine so ausgeprägten Bemühungen von Europäern, Einfluss auf Kirche und Staat zu bekommen. Die Herrschaft von Tewodros II. war geprägt vom Versuch, konsequent europäisches Wissen und Konzeptionen angefangen von Handwerk bis hin zu theologischen Neuerungen - einzuführen und feste Beziehungen mit europäischen Staaten zu knüpfen. In seine Zeit fallen auch die Gründung erster Missionsschulen und schließlich auch der Beginn der Ausbildung von Äthiopiern in ausländischen Schulen.

1855 reiste eine Delegation der St. Chrischona-Pilgermission aus Basel nach Äthiopien, die aus dem Missionar Johann Ludwig Krapf aus Kornthal, dem Handwerker-Missionar Johann Martin Flad aus Undingen und dem AmharischLehrer und Übersetzer Mahdärä Qal bestand, und wurde von Tewodros II. freundlich empfangen. 1856 etablierte sich die Abessinien-Mission der St. Chrischona-Pilgermission dauerhaft in Gafat bei Däbrä Tabor und bei den «Falascha», insbesondere in Ğända (beide in Bägemdər). Nur für die von Krapf ebenfalls erhoffte Oromo-Mission gab der König der Könige keine Erlaubnis, so dass diese erst 1867 beginnen konnte (sich aber nach einem ersten Misserfolg in Beni-Schangul und Gubbe im westäthiopischen Grenzgebiet erst 1871 im Königreich Šäwa etablierte). ${ }^{3}$ Die Präsenz dieser Mission in Äthiopien führte zur Herausbildung einer Gruppe junger europäisch gebildeter Äthiopier, von denen mehrere später als Missionare und politische Beamte im Äthiopien des Yohannəs IV. und Mənilək II. eine zum Teil bedeutende Rolle spielten.

Die Mission regte unter ihren lokalen Anhängern auch Versuche an, mit den externen Leitern der Mission in Europa und Jerusalem Kontakt aufzunehmen. Wir besitzen daher aus dieser Zeit Briefe der bedeutendsten äthiopischen Förderer der Mission: von dem Sekretär des äthiopischen Herrschers, aläqa Zännäb, ebenso wie von dem konvertierten Gelehrten der Betä Hsra ${ }^{2}$ l, Bərru Wəbe. Nach 1865, bis zum Sturz Tewodros II.', sind keine Briefe von Äthiopiern mehr überliefert — außer von Tewodros II. selbst, — da in jenem Jahr die Abessinien-Mission de facto zusammenbrach. Die ersten Europäer wurden vom König der Könige gefangengesetzt, die Missionare zu Zwangsarbeiten verpflichtet und schließlich ebenfalls in Ketten gelegt. Dies führte zu der bekannten Intervention britisch-indischer Truppen aus Bombay und London im Jahre 1867/68 unter dem Kommando von Sir Robert Napier und dem Sturz und Selbstmord des Herrschers - und zur Landesverweisung aller Europäer, denen einige ihrer äthiopischen Missionsschüler nach Jerusalem (und später

${ }^{3}$ Zur Geschichte dieser ersten protestantischen Mission bei den Oromo siehe Smidt, Wolbert G. C., «The Role of the Former Oromo Slave Pauline Fathme in the Foundation of the Protestant Oromo Mission», in: Böll, Verena — MArTínez D’ AlòsMoner, Andreu - Kaplan, Steven - Sokolinskaia, Evgenia (eds.), Ethiopia and the Missions. Historical and Anthropological Insights, Münster 2005, 77-98. 
Basel) folgten. ${ }^{4}$ Allerdings nahm die Mission bei der ersten sich bietenden Gelegenheit 1869 ihre Arbeit wieder auf — und zwar im de facto unabhängigen Təgray im wieder zerfallenen äthiopischen Königreich. Ein Willkommensbrief für die ersten aus Jerusalem zurückkehrenden Missionare hat sich erhalten. Mit ihm endet diese Zusammenstellung, da er ein neues historisches Kapitel eröffnet, aber auch noch an der seit 1856 etablierten Mission anknüpft.

\section{Zur Bedeutung der äthiopischen Missions-Briefe}

Die erhalten gebliebenen äthiopischen Korrespondenzen dieser Zeit, die in Missionsrundschreiben vervielfältigt wurden, zum Teil in Archivsammlungen überliefert wurden, sind insbesondere wegen ihrer Seltenheit einzigartige historische Dokumente, Zeugnisse dieser ersten äthiopischen Moderne, die den historischen Wandel Äthiopiens an Einzelbeispielen illustrieren. Es ist dabei sicherlich etwas kurios, aber signifikant, dass einer oder gar mehrere der Briefe im Original auf Deutsch abgefasst wurden. Die Verbindung der Missionare mit ihren wenigen Schülern war so eng, dass einige der jungen Äthiopier bereits in Äthiopien Deutsch lernten. ${ }^{5}$ Dies eröffnete einigen von ihnen später die Möglichkeit, im Ausland ihre Ausbildung fortzusetzen womit sie zu den ersten Afrikanern gehörten, die aus eigenem Antrieb zur Ausbildung nach Europa gingen.

Die Dokumentation und Erforschung äthiopischer Korrespondenzen sind, das ist spätestens seit den Acta Aethiopica von Sven Rubenson deutlich, von entscheidender Bedeutung zum Verständnis der politischen Geschichte und der Geistesgeschichte Äthiopiens. Die klassischen theologischen und historischen Werke Äthiopiens werden als zentrales Thema der Äthiopistik seit langem erforscht. Weniger im Zentrum des geistesgeschichtlichen Interesses standen bisher scheinbar marginale Quellen wie diese. In der Geschichtsforschung wird aber zu Recht seit einiger Zeit Wert auch auf originale Zeugnisse einzelner Individuen gelegt, die mehr Teilnehmer als Akteure der «großen» geschichtlichen Ereignisse sind. An ihnen ist Mentalitätswandel, der Wandel von Paradigmen, von Topoi, der vitalen Interessen dieser Teilnehmer des geschichtlichen Prozesses ablesbar — aber auch die Kontinuität alter Muster und Vorstellungen.

${ }^{4}$ Vgl. dazu Smidt, Wolbert G. C., «"Schwarze Missionare” im Deutschland des 19. Jahrhunderts», in: BechHaus-Gerst, Marianne - Klein-Arendt, Reinhardt (Hrsg.), AfrikanerInnen in Deutschland und schwarze Deutsche - Geschichte und Gegenwart, Münster - Hamburg 2004 (Encounters / Begegnungen, 3), 41-56; SMIDT, Wolbert G. C., «Les Africains de Bâle du 19ème siècle», in: David, Thomas et al. (eds.), De la traite des Noirs à la fin du régime de l'Apartheid: trois siècles de relations entre la Suisse et l'Afrique (XVIIIe-XXIe siècles), Münster: Lit-Verlag (im Erscheinen).

5 Vgl. u. a. Flad, FrIEdrich, Michael Argawi. Ein mutiger Bekenner und Zeuge unter den Falascha in Abessinien, bearbeitet von WERnER SIDLER, Basel 1952, 9. 
Der leider verstorbene Sewir B. Chernetsow hat auf der 15. internationalen Konferenz der äthiopistischen Studien im Juli 2003 in Hamburg in mehreren persönlichen Gesprächen (darunter auch mit dem Autor) angeregt, dass éthiopisants verschiedener Länder (insbesondere Deutschland bzw. Schweiz, Frankreich, Schweden, Italien) nach solchen Korrespondenzen fahnden und zwar aus dem Umkreis der Mission. ${ }^{6}$ Der Beitrag der Mission zur Modernisierung und Reform Äthiopiens war im 19. und frühen 20. Jhdt. von großer Wichtigkeit. Die sicherlich häufig noch unentdeckten Briefe in Missionsarchiven würden, einmal zusammengestellt, so seine Meinung, einen wichtigen Beitrag zur äthiopischen Geistesgeschichte bieten. Eine solche Sammlung stünde nicht in Konkurrenz zu den Acta Aethiopica, die Sven Rubenson in jahrzehntelanger Sammelarbeit zusammengestellt hat (und auf deren 4. Band man hoffnungsvoll wartet), da jene sich auf Briefe in äthiopischen Sprachen konzentrieren und (wohl wegen des Schwerpunktes auf politische Geschichte) die zahlreichen Briefe der äthiopischen Missions-Zöglinge oder Helfer kaum aufgenommen haben. Chernetsows Vorschlag bezieht sich seinerseits nur auf Briefe von Äthiopiern aus dem Umkreis der Mission, zielt also auf eine thematische Konzentration. Als ersten Schritt, auch zur Anregung anderer éthiopisants, möchte ich anlässlich seiner Festschrift hier das erste Ergebnis meiner eigenen Recherchen in den Archiven der St. Chrischona-Pilgermission in St. Chrischona/Bettingen und im Staatsarchiv Basel, wo zahlreiche Dokumente der deutschen und schweizerischen Missionare in Äthiopien zur Zeit des Königs der Könige Tewodros II. aufbewahrt werden, vorstellen.

Welche Themen stehen im Zentrum dieser Briefe? Etwas enttäuschend mag es für den Historiker sein, aber gleichzeitig für den Geistesgeschichtler eine bemerkenswerte Tatsache, dass die Briefe (sogar die aus den für das Ende der Mission so entscheidenden Jahren von 1864/65) die politische Situation praktisch nicht widerspiegeln. Im Zentrum stehen christliche Formeln und knappe theologische Überlegungen. Diese stehen für neue Entwicklungen in Äthiopien, die die Mission teilweise angestoßen hatte. Interne Auseinandersetzungen um theologische Fragen hatten durch die Präsenz der Mission eine internationale Dimension bekommen (dieser Aspekt klingt auch in dem warnenden Brief des abunä Sälama an). Ein typisches Beispiel für diese neuen Entwicklungen, das auch für die moderne äthiopisch-orthodoxe Kirche Folgen hatte, ist z.B. die Frage des Gebrauches des amharischen Sprache: Durch Tewodros II. gefördert, kamen in Bruch mit der Tradition amharische Bibeln in Gebrauch; die ersten amharischen Texte der Moderne - wie die Chronik der Regierungszeit Tewodros II. des aläqa Zännäb, ${ }^{7}$ eines Anhängers der Mission — entstanden. In den Briefen taucht das Topos der Bosheit

\footnotetext{
${ }^{6} \mathrm{Vgl}$. dazu auch Chernetsov, SeVIR, «Epistolography», in: EAE II, 340-342.

${ }^{7}$ Däbtära ZännäB, The Chronicle of King Theodore of Abyssinia, ed. by ENNO Littmann, Princeton, NJ 1902; Übersetzung: Moreno, Martino Mario, «La Cronaca
} 
oder der Finsternis, von der die Briefschreiber von den Missionaren befreit worden waren, mehrfach auf - Europa wird indirekt als die Quelle des Lichts angesehen. Eindrucksvoll ist, wie insbesondere der traditionelle Gelehrte däbtära Bərru einen Großteil seines Briefes aus Bibelzitaten aufbaut, woraus er ein eindringliches Bekenntnis komponiert.

Die meisten Briefe haben sich im Original nicht erhalten, sondern häufig nur in Form von Abschriften oder gar nur lückenhaften Auszügen und Übersetzungen, in Handschrift oder gedruckt in kleinen Rundschreiben der St. Chrischona-Pilgermission (nach Aufbau und Zielsetzung sind diese gewissermaßen vergleichbar mit den Spendenbriefen heutiger $\mathrm{NGOs}^{8}$ - und darum auch in keiner Bibliothek außer in der St. Chrischona-Pilgermission erhalten geblieben). Das erste Dokument ist ein von Tewodros II. nicht lange nach seiner Krönung geschriebener, bisher nicht in seiner deutschen Version $^{9}$ veröffentlichter Brief. Dieser enthält eine Einladung an die protestantischen Handwerker-Missionare, ${ }^{10}$ nach der Vertreibung der katholischen Mis-

di Re Teodoro attributa al Dabtarā "Zaneb”», RSE 2-2, 1942, 143-180. Die Zuschreibung an Zännäb scheint mir unzweifelhaft, da der Missionar Flad, der ihn aus Mäqdäla kannte und dieses Manuskript selbst nach Europa mitbrachte, ihn als Autor nannte. Siehe FLAD, 60 Jahre in der Mission.

${ }^{8}$ Die Jahresrundschreiben und die häufiger im Jahr (zuletzt sechs Mal) erscheinenden Mittheilungen aus der Correspondenz der Pilgermission, zunächst für deren auswärtige Brüder bestimmt wurden in Kreisen der Missionare und Missionsfreunde versandt und erfüllten zwei Aufgaben: Erstens wurden diese so über die Entwicklung der fortlaufenden Missionsprojekte informiert und zweitens somit auch zu weiteren Spenden angeregt. Die Mission litt immer an erheblicher Geldknappheit; insbesondere in England fanden sich immer wieder großzügige Spender, weshalb mehrere der in den Mittheilungen veröffentlichten Briefe auch in englischer Sprache versandt wurden. Die Funktion der äthiopischen Briefe in diesem Zusammenhang ist evident: Sie dokumentieren den Erfolg der Mission.

${ }^{9}$ D. Appleyard und R. Pankhurst haben das Original in englischen Archiven gefunden, siehe ApPleyard, David L. - PAnkhurst, Richard, Letters from Ethiopian Rulers (Early and Mid-Nineteenth Century), Oxford 1985 (Oriental documents, IX), 135-142, und Rubenson hat es erneut in Acta Aethiopica II als no. 5 veröffentlicht: RUBenson, Sven (ed.), Tewodros and his Contemporaries, 1855-1868, Addis Ababa Lund 1994 (Acta Aethiopica II), 11. Da der Brief die Mission gewissermaßen einleitet, ist die deutsche Übersetzung auch von Interesse, weshalb sie hier wiedergegeben wird.

${ }^{10}$ Der Kontext des Briefes, in dem Tewodros II. die Bitte um «Arbeiter» mit Vorschriften über deren Verhalten in Fragen der Mission verbindet, zeigt, dass ihm der missionarische Kontext des Angebots der Entsendung von Handwerkern durch Bischof Gobat in Jerusalem bewusst war. Seine Vorbedingung, dass sie keine Priester sein dürften, führte dazu, dass die entsandten Handwerker-Missionare nicht geweiht wurden, sondern Laien blieben. Sämtliche Konvertiten der «Falascha» wurden daher von äthiopischen Priestern getauft und so formal in die äthiopisch-orthodoxe Kirche aufgenommen. Der spätere Brief von abunä Sälama von 1862 bezieht sich auch auf diese Tatsache. Das Ziel der Mission war nicht die Gründung einer eigenen 
sion in das Land zu kommen. Historisch vielleicht noch interessanter ist der einige Jahre später geschriebene bisher unbekannte Brief des Metropoliten Äthiopiens, abunä Sälama. Dieser enthält eine Entscheidung, nach der die Missionare theoretisch die Möglichkeit eingeräumt bekamen, ihre Lehre frei von den Vorschriften der äthiopisch-orthodoxen Kirche außerhalb ihrer Gebiete zu unterrichten - was später in den Oromo-Regionen tatsächlich begonnen wurde und in letzter Konsequenz zur Gründung einer eigenen protestantischen äthiopischen Kirche führte. Es ist allerdings dabei nicht zu vergessen, dass die meisten Gebiete und Länder der Oromo sich damals noch außerhalb des äthiopischen Reiches befanden. Der Brief enthält aber auch die schon zu Beginn der Mission von Tewodros deutlich ausgesprochene Warnung, dass im Kerngebiet Abessiniens keinesfalls eine eigenständige Kirche entstehen dürfe. Die übrigen Briefe sind meist von Missionszöglingen und Freunden der Mission geschrieben, darunter von Persönlichkeiten wie dem oben bereits genannten aläqa Zännäb, einer zentralen Figur der modernen Literaturgeschichte Äthiopiens, und von dem noch sehr jungen Missionsschüler Arägawi, bekannt als Mika ${ }^{2} e l$ Arägawi, der später der bedeutendste protestantische äthiopische Missionar werden sollte. ${ }^{11}$ Weitere Missionsschüler, die später ihre Ausbildung in Europa erhielten, tauchen in diesen Dokumenten erstmals auf.

Die Originalsprache der Briefe wird nirgendwo direkt angesprochen, doch waren sie meist sicherlich in Amharisch abgefasst. Eine Ausnahme ist der Brief des Arägawi, der um Nachsicht für seine Fehler im Deutschen bittet; sein Brief scheint also bereits im Original auf Deutsch abgefasst worden zu sein. Die Briefe sind hier in Wortlaut, Rechtschreibung und Punktuation genauso wiedergegeben, wie sie vorgefunden wurden. Die Übersetzer sind nur im Falle des ersten und des letzten Briefes dieser Sammlung bekannt. Beim ersten Brief war dies Johann Ludwig Krapf, der früher bereits als Missionar in Təgray und Šäwa gewirkt hatte, beim letzten der Handwerkermissionar Johannes Mayer. In den anderen Fällen ist wohl häufig Krapf (bei Nr. 5 Flad?) erneut der Übersetzer gewesen; in seinen im Staatsarchiv Basel-Stadt vorhandenen Korrespondenzen erwähnt er gelegentlich, dass er amharische Briefe erhielt. Wie der Vergleich der ersten Briefübersetzung mit dem überlieferten amharischen Original zeigt, ist die Übersetzung in diesem Fall recht wortgetreu. Allerdings interpretierte sie auch leicht, wo es das Verständnis erforderte (das Wort für «Rad» wird dem Zusammenhang entsprechend als «Schraube» wiedergegeben). Dieses Beispiel aber zeigt, dass insgesamt von großer Nähe zum Originaltext ausgegangen werden kann. Bibelzitate dürften einer dem Übersetzer vorliegenden deutschen Bibelfassung angelehnt worden sein.

äthiopischen protestantischen Kirche, sondern die Anregung innerkirchlicher Reformen in Äthiopien.

${ }^{11}$ Vgl. seine Biographie: FlaD, Michael Argawi. Ein mutiger Bekenner. 


\section{Die Briefe:}

\section{Nəgusä nägäst Tewodros II. an Bischof Samuel Gobat in Jerusalem $1855^{12}$}

Möge dieses Schreiben (Sendung) ${ }^{13}$ welches gesendet wird von Theoderos, dem von Gott eingesetzten König der Könige gelangen an den englischen Bischof Gobat in Jerusalem.

Bist du sehr wohl? - Der Brief den du mir durch Krapf u. Martin Flad gesandt hast, hat mich erreicht. Es freute mich, daß du nach mir fragst. Wenn nun diese bleiben so behalte sie mir. Und wenn die Leute von denen du mir sagtest, sagen, wir gehen (nach Habesch) so werde ich sie in Liebe aufnehmen, u. in Liebe senden..$^{14} \mathrm{Da} ß$ du sagst, ich will dir Arbeiter senden, freute mich, sende sie mir. Aber du kennst die Verhältnisse unseres Landes in dem du gewesen bist. ${ }^{15}$ Es war früher in 3 Theile getheilt, ${ }^{16}$ aber durch Gottes Kraft habe ich Einheit gestiftet. Priester welche den Glauben vertreiben (ver-

${ }^{12}$ Die Übersetzung des Briefes ist enthalten in dem Schreiben des Sattlergesellen und Laienmissionars Martin Flad aus Alexandrien vom 15.8.1855, das dieser auf der Rückkehr von seiner ersten Reise nach Abessinien an den Missionsgründer Spittler in Basel sandte. Der Missionar Krapf, mit dem er diese Reise unternahm, hat den Brief ins Deutsche übersetzt; zu Beginn dieses Dokumentes hat Flad notiert: «Schreiben des Königs von Abessynien an Bischof Gobat in Jerusalem! (Ziemlich wortgetreue Uebersetzung.)» — Das amharische Original des Briefes ist abgedruckt in: RuBenson, Tewodros and his Contemporaries, 10f., no. 5, und auch in: Appleyard PANKHURST, Letters from Ethiopian Rulers, 135-142, no. XXVI. Eine gesiegelte Kopie dieses Briefes, die nicht verwendet wurde, war im Besitz von Johann Ludwig Krapf und später von Martin Flad; sie ist im Besitz von Nachkommen des Letzteren und wird hiermit erstmals publiziert (siehe Pl. Ix, Annex).

${ }^{13}$ Klammern sind offenbar erklärende Einfügungen des Übersetzers.

${ }^{14}$ Diesen Abschnitt hat der Übersetzer Krapf mißverstanden, wie das in: RuBENson, Tewodros and his Contemporaries, 10f. veröffentlichte Original zeigt; insbesondere «Wenn nun diese bleiben so behalte sie mir» ist hier ganz unverständlich Tewodros zitiert damit Gobat. Rubenson hat folgende Übersetzung: «But when these people of whom you said to me, "If they stay, protect them for me; if they come [back], send them to me under protection", told me that they [Flad und Krapf] would leave, [as] I had received them with love, I sent them away with love».

${ }^{15}$ Tewodros kannte Gobat aus seiner Kindheit, als Gobat als Missionar in Nordäthiopien tätig war; der heilkundige Gobat hatte däğğazmač Kinfu, Haylu, den älteren Halbbruder von Tewodros, der ihn aufzog, wegen einer Neurose behandelt (vgl. Gobat, Samuel, Samuel Gobat, evangelischer Bischof in Jerusalem. sein Leben und Wirken meist nach seinen eigenen Aufzeichnungen, bearbeitet von SPITTLER, CHRISTIAN FrIEDRICH, Basel 1884).

${ }^{16}$ Im Original ist dieser Satz länger, aber der Sinn ändert sich nicht; RUBENSON, Tewodros and his Contemporaries, 11, hat: «It had been divided, one against another, even into three». 
stören) sollen nicht zu mir kommen, ${ }^{17}$ daß unsere Liebe nicht nachlasse. Früher hat der sogenannte Vater Jakob ${ }^{18}$ die Taufe aufgehoben, $u$. hat Diacone u. Priester gemacht u. hat viele Dörfer zum Abfall bewogen. Durch Gottes Gnade habe ich ihn vertrieben u. weggesandt. Wenn aber ein anderer kommt, so will ich ihn in Liebe aufnehmen, u. in Liebe entlaßen, - - u. wenn er bleiben will, will ich mit Freuden bleiben lassen (im Lande.). ${ }^{19}$ Ich höre, daß es etwas giebt, das mit einer Feuerschraube ${ }^{20}$ pflügt. - Einer von den Arbeitern soll mit dieser Schraube kommen. - Und du frage nach mir - ich werde auch nach dir fragen. Zum Preise Gottes habe ich seit 2 Jahren durch den Herold (öffentlich) den Sklavenhandel verboten.

Enthalten im Schreiben von Martin Flad aus Alexandrien vom 15.8.1855, Staatsarchiv des Kantons Basel-Stadt, Privatarchiv Spittler / PA 653, Signatur «V, Joh. Martin Flad».

${ }^{17}$ Mir scheint, dass Rubenson diese Stelle deutlich zu sehr zuspitzt, wenn er sagt (Rubenson, Tewodros and his Contemporaries, 11, Fußnote): «The above letter is primary evidence that Tēwodros made it abundantly clear from the outset that the missionaries would be welcome as useful craftsmen but not as missionaries». Die ganz formale Bedeutung des Wortes «Priester», um die es hier geht, ist offenbar wichtig: Aus dem späteren guten Verhältnis der entsandten Handwerkermissionare zum Herrscher (bis zur Zuspitzung des Misstrauens Tewodros' England gegenüber und zum Teil aber sogar darüber hinaus andauernd), deren Gesprächen über Religion, Tewodros' Versuchen, auf Anregen der Missionare das Amharische in der Kirche zu fördern, Tewodros' Unterstützung der Missionsschulen etc. wird deutlich, dass er deren religiösen Tätigkeit in der ersten Hälfte seiner Regierungszeit positiv gegenüberstand - abgesehen davon, dass Flad und Krapf schon bei ihrem Besuch 1855 nicht verhehlten, dass die Handwerker auch religiös tätig werden sollten. Gobat hatte dann, Tewodros' Anordnung folgend, keine ordinierten Priester gesandt, sondern als Laienmissionare tätige Handwerker. Auch spätere Äußerungen äthiopischer Herrscher zeigen die zentrale Bedeutung dieses Beschlusses — wenn Missionare kamen, so sollten sie es «wie Flad» machen, d.h. Konversionen sollten zum Eintritt der Konvertiten in die äthiopisch-orthodoxe Kirche führen. Rubenson übersieht somit den auch formalistischen Charakter von Tewodros' Bedingung. (Zur Forderung, es «wie Flad» zu machen, siehe Manuskript von Heintze-Flad, Wilfred, Martin Flad, Villars-Tiercelin 2000).

${ }^{18}$ Der katholische Missionar Giustino de Jacobis, von der katholischen Bevölkerung noch heute abunä Yaqob oder qəddus Yaqob (seltenere Variante «Ya ${ }^{\supset}$ əqob») genannt.

${ }^{19}$ Rubenson, Tewodros and his Contemporaries, 11: «Whoever stays, I shall make happy and provide for».

${ }^{20}$ Eigentlich «Feuerrad» im Amharischen (vgl. RuBENSON, Tewodros and his Contemporaries, 11, der dies aber nicht erklärt); die Beschreibung zeigt, dass nur ein maschinell angetriebener Pflug gemeint sein kann. Der Überlieferung in der Familie Flad nach, handelt es sich um einen (frühen) «Traktor», d.h. einen dampfbetriebenen Pflug; Tewodros «wanted even Gobat to send him a tractor and a tractor driver», s. Manuskript von HeInTZE-Flad, Martin Flad, 8. 


\section{Däbtära Zännäb ${ }^{21}$ [«Debtera Saneb»] und däbtära Mäsqäl ${ }^{22}[\ll$ Mas- kal»]}

an Samuel Gobat, anglikanischer Bischof von Jerusalem [Mäqdäla] ${ }^{23}$ Oktober/November $1861^{24}$

Dieser Brief, gesandt von Debtera Saneb und Debtera Maskal, gelange an Samuel Gobat. Im Namen unseres Herrn Jesu Christi — wie befinden Sie sich? Wir sind, dem Herrn sei Dank, wohl. — Die Brüder, die Sie zu uns gesandt, haben das Licht Jesu Christi ${ }^{25}$ in unseren Herzen verbreitet. Wenn Sie vielleicht sagen: Den Müden gebe ich Ruhe, und die Starken stelle ich an den Streit, bitten wir daß Sie nicht müde werden. Wir sind der Sünden Sklaven, bitten wir Sie aber um unsers Herrn Jesu Christi willen, in Gemeinschaft mit Ihren Brüdern für uns zu beten, daß das Geheimnis seines Reiches in unserm ganzen Lande möge verbreitet werden. Zwar wissen wir, daß Sie für uns beten; aber wir wünschen, daß Sie in Ihrer Fürbitte für uns noch mehr erstarken mögen.

Gedruckt in: Mittheilungen, Nr. 1, Juni 1862, 2. [Langtitel siehe Fußnote 8]

\section{Däbtära Zännäb und däbtära Mäsqäl}

an die Bibel-Gesellschaft in London

[Mäqdäla] Oktober/November $1861^{26}$

Dieser Brief, gesandt von Debtera Saneb und Debtera Maskal, möge gelangen an die Bibelgesellschaft in London.

${ }^{21}$ Zännäb war als Sekretär von Tewodros II. auch dessen Chronist. In der Biographie des Missionars Flad heißt es über seine Verbindung zu den Missionaren: «Ein gelehrter Mönch, der Schreiber des König Theodorus, der im Jahre vorher [1857] schon durch die Missionare Kienzlen und Meier die amharische Bibel kennengelernt hatte, wurde der erste Evangelist aus der äthiopischen Bevölkerung». (FLAD, JuLIUS, Johann Martin Flad. Ein Leben für Äthiopien, Gießen - Basel: Brunnen-Verlag 1968, 32; so erzählt es auch Martin Flad selbst, siehe FLAD, 60 Jahre in der Mission, 105).

${ }^{22}$ Bruder von däbtära Zännäb (vgl. STREBEL, «Leben auf dem Missionsfeld», 138).

${ }^{23}$ Zännäb war nach den Briefen der Missionare in Mäqdäla stationiert; er gab dreimal wöchentlich den Soldaten auf der Bergfeste Bibelstunden und einmal wöchentlich eine Gebetsstunde. Bei Flad lernte er Englisch, um seine amharische Bibel mit der englischen vergleichen zu können (FLAD, 60 Jahre in der Mission, 105).

${ }^{24}$ Am 4. Dezember 1861 schickt Martin Flad Abschriften der Briefe, die er «kürzlich» erhalten hat, an C. F. Spittler in Basel, siehe Mittheilungen, Nr. 1, Juni 1862, 1.

${ }^{25}$ Anspielung auf Joh 8:12: «Ich bin das Licht der Welt; wer mir nachfolgt, der wird nicht wandeln in der Finsternis, sondern wird das Licht des Lebens haben».

${ }^{26}$ Wie Fußnote 24: am 4. Dezember 1861 schickt Martin Flad Abschriften der kürzlich erhaltenen Briefe an C. F. Spittler in Basel, siehe Mittheilungen, Nr. 1, Juni 1862, 1. Flad notiert am Ende dieses Briefes, Seite 3: «Diesem Brief ist noch ein Formular beigelegt mit einem Bittschreiben, amharische Bibeln in Taschen-Format drucken zu lassen». 
Im Namen unseres Herrn Jesu Christi — wie befinden Sie sich? Die Brüder, welche durch S. Gobat ${ }^{27}$ zu uns gesandt sind, haben die Liebe Christi in unseren Herzen wohnend gemacht. Zuvor saßen wir in großer Finsterniß, und nun freuen wir uns im Lichte des Evangeliums. ${ }^{28}$ Zwar sind wir noch böse, bitten aber unserer deßhalb nicht müde zu werden, sondern für uns den Vater Jesu Christi zu bitten, daß die Sache Christi, die zu uns kam, möge bei uns so geehrt werden, wie sie bei Ihnen geehrt wird. Daß Sie für uns beten, wissen wir; schreiben aber diese Zeilen, daß Sie noch mehr für uns beten mögen.

Gedruckt in: Mittheilungen, Nr. 1, Juni 1862, 2f.

\section{Abunä Sälama [«Abuna Salama»]}

an Friedrich Brandeis ${ }^{29}$ und Wilhelm Staiger ${ }^{30}$ in Gafat Mäqdäla, Oktober/November ${ }^{31} 1862$

Abuna Salama, Bischof von Abessinien, an W. Staiger und F. Brandeis. Grüße zuvor. Den Brief, welchen ihr mir zugeschickt habt, habe ich erhalten.

${ }^{27}$ Die Laienmissionare wurden in der St. Chrischona-Pilgermission ausgebildet und entsandt, die Leitung lag aber in den Händen des anglikanischen Bischofs Samuel Gobat in Jerusalem; Gobat war 1832-1834 als einer der ersten protestantischen Missionare in Äthiopien, gefolgt von Johann Ludwig Krapf, der nun als Mitglied des Komitees der St. Chrischona-Pilgermission ebenfalls bedeutenden Einfluss auf die Mission ausübte. Gobats Instruktionen an die Missionare vom 7. Dezember 1855 sind abgedruckt in WALDMEIER, THEOPHILUs, The Autobiography of Theophilus Waldmeier: Being an Account of Ten Years' Life in Abyssinia; and Sixteen Years in Syria, London — Leominster o.J. [1886/87], 46-58.

${ }^{28}$ Bezug auf Matth 4:16: «Das Volk, das in Finsternis saß, hat ein großes Licht gesehen, und denen, die im Land und Schatten des Todes saßen, ist Licht aufgegangen» (Angelehnt an Jes 9:1).

${ }^{29}$ Früher Eleazar Brandeis, dann vom Judentum zum Protestantismus konvertiert und schließlich Missionsschüler auf St. Chrischona; dies prädestinierte ihn zu der im 19. Jhdt. besonders aktiv betriebenen «Judenmission», als deren Teil die Mission unter den «Falascha» verstanden wurde. $\mathrm{Zu}$ seiner Biographie siehe STREBEL, BARBARA, «Brandeis, Friedrich Wilhelm», in: EAE I, 621, und zu seiner Rolle in der Mission siehe STREBEL, «Leben auf dem Missionsfeld».

${ }^{30}$ Brandeis und Staiger, die mit Flad 1856 aus St. Chrischona gekommen waren, waren damals in den Dienst einer schottischen Missionsgesellschaft getreten und hatten eine weitere Missionsstation der «Falascha-Mission» gegründet (vgl. FLAD, Johann Martin Flad. Ein Leben für Äthiopien, 35).

${ }^{31}$ Am Tag nach Erhalt des Briefes ging Staiger in Begleitung von Kienzlen zum König nach Däbrä Tabor, der die Erlaubnis zur Abreise nach Dämbəya gab (unter Zeugenschaft eines abessinischen Priesters und Kienzlens), damit sie dort den Unterricht unter den «Juden» beginnen könnten. Sie reisten daraufhin am 27. November 1862 in Begleitung eines Mannes des Königs ab (vgl. Mittheilungen, Nr. 2, Juni 1863, 14). 
Wenn es sich ergibt, daß ich mit dem Könige zusammen komme, ${ }^{32}$ will ich Alles berathen. Vorderhand aber, wenn ihr das Evangelium unsers Herrn und Heilandes Jesu Christi unter den Nationen verkündigen wollt, bin ich nicht dagegen. Jedoch liebe ich nicht in Abessinien zwei Kirchenpartheien und zwei Glaubensbekenntnisse. Wenn ihr aber lehrt wie Herr Flad, und die etiopischen Priester eure Proselyten taufen laßt, so mögt ihr immerhin unterrichten; allein daß ihr nicht gegen das Evangelium Sachen lehrt, welche uns in der Liebe entzweien. Wenn ihr aber in ein anderes Land gehen wollt, z.B. zu den Gallas, in ein Land, in welchem das Christenthum noch nicht ist, und in welchem noch keine Priester sind, mögt ihr immerhin thun, wie euch der König erlaubt ${ }^{33}$.

Gedruckt in: Mittheilungen, Nr. 2, Juni 1863, 13

5. Die «bekehrten Falascha» [Däbtära Bərru Wəbe und andere ${ }^{34}$ ] an die London Society for Promoting Christianity Amongst the Jews [«unsere Gesellschaft»]

Ğända, nach 21. Juli $1862^{35}$ [vor 1863]

Im Namen Gottes des Vaters, des Sohnes und des hl. Geistes, Ein Gott. Amen. ${ }^{36}$ Möge dieser Brief gelangen an die Gesellschaft in England, die

32 Tewodros war in der Zeit mit seiner Armee bei Däbrä Tabor, vgl. Mittheilungen, Nr. 1, Juni 1863, 13.

${ }^{33}$ Diese Bemerkung ist historisch von einiger Wichtigkeit. Offenbar da zu jenem Zeitpunkt zahlreiche Oromo-Gebiete und -Länder noch nicht oder kaum unterworfen waren, beansprucht der abun keine Priorität der äthiopisch-orthodoxen Kirche, sondern überlässt die Entscheidung über die eventuelle Selbständigkeit der protestantischen Mission ganz dem König. Diese Entscheidung kann als erster Schritt zur Legitimierung einer zukünftigen unabhängigen protestantischen Kirche unter den Oromo angesehen werden. Noch war ein solcher Schritt allerdings in weiter Ferne, zumal die Oromo-Gebiete unzugänglich blieben; erst mit der ab 1871 unter nəgus Mənilək in Šäwa etablierten protestantischen Mission wurden die ersten Oromo-Gebiete erreicht.

${ }^{34}$ Dieser gelehrt abgefasste Brief ähnelt dem Nachfolgenden des däbtära Bərru sehr, weshalb vermutet werden kann, dass dieser Brief ebenfalls von ihm abgefasst worden ist.

35 «Ein Brief der bekehrten Falascha...», ohne weitere Angabe. Nach FLAD, 60 Jahre in der Mission, 117 ist der 21. Juli 1862 das Taufdatum von däbtära Bərru und 21 weiteren Konvertiten (der erste große Erfolg der Mission in Ğ̈äda); am 4. August 1862 wurden 19 weitere getauft und später noch weitere 24. Die Reihenfolge in Flads Bericht und der Briefinhalt zeigen, dass er nicht in großem zeitlichen Abstand (danach) geschrieben worden ist. Es ist also nicht Rubenson (RubEnson, Tewodros and his Contemporaries, 179 [Fußnote]) zu folgen, der den Brief etwas früher datiert.

${ }^{36} \mathrm{Im}$ Gegensatz zu den anderen hier abgedruckten Briefen beginnt dieser Brief mit der klassischen Anfangsformel von christlichen äthiopische Briefen; er ist somit eindeutig eine Übersetzung. Diese Übersetzung durch Flad unterscheidet sich nur in 
Lehrer und Bibeln sandte zu den zerstreuten Kindern Israels ${ }^{37}$ in Abessinien. Er ist gesandt von den Falascha in Dschenda, welche an Jesum Christum glauben. Teure Väter, ${ }^{38}$ wie befinden Sie sich? ${ }^{39}$ Wir waren ohne Erkenntnis, in großer Finsternis; aber jetzt, seitdem Sie uns Lehrer sandten, sind wir, obgleich wir viel mit ihnen disputierten, doch an der Wahrheit gelangt ${ }^{40}$ wie Jesaias sagt: «Das Volk, das im Finstern wandelt, hat ein großes Licht gesehen, und die da saßen am Ort und Schatten des Todes, denen ist ein Licht aufgegangen» ${ }^{41}$ Und nun, teure Väter, nehmet uns in Eure Sorge und betet für uns, damit wir empfangen die Gnade des Herrn und darin befestigt werden, denn wir sind gleich zarten Pflanzen, die noch nicht tiefe Wurzel haben. Sie haben uns Gutes getan, wie David sagt: «Ich will Übertreter deine Wege lehren und Sünder zu dir bekehren». ${ }^{42}$ Und wie Jesaias sagt: «Er soll aufwachsen vor ihm als eine zarte Pflanze, als eine Wurzel aus einem trockenen Erdreich». ${ }^{43}$ Diese Worte wenden wir auf uns selbst an, denn wir waren, ohne Ihn zu kennen, seine Feinde! Dieses schreiben wir Ihnen, damit Sie für uns vor dem Herrn ringen mögen. Ehre sei dem Vater, dem Sohn und dem heiligen Geist. Amen. ${ }^{44}$

Gedruckt in: FLAD, 60 Jahre in der Mission, 118. Englische Version in: Jewish Intelligence, and Monthly Account of the Proceedings of the London Society for Promoting Christianity Amongst the Jews 29, March 1863, 68f. (Siehe auch Acta Aethiopica II, no. 103: Rubenson, Tewodros and his Contemporaries, 179).

wenigen Details von der englischen Übersetzung, die aber insgesamt näher am Original sein dürfte. Jedoch ergeben sich durch die Unterschiede keine anderen Interpretationsmöglichkeiten.

${ }^{37}$ In dieser Formulierung verbirgt sich eine Selbstbezeichnung der «Falascha»: Däqqä Gsra ${ }^{2}$ l, oder vielleicht sogar «Betä Bsra ${ }^{2}$ el» (heute als Ethnonym verwendet). Interessant ist, dass die Schreiber sich in diesem Brief selbst als «Falascha» bezeichnen, was eigentlich Fremdbezeichnung ist. Sie wird hier ohne Einspruch aus dem Amharischen übernommen (von der Wurzel fälläsä, bedeutend etwa «die Vertriebenen», siehe KaPlAN, SteVEN, «Betä Gsra ${ }^{2}$ el», in: EAE I, 552-559).

${ }^{38}$ In der englischen Fassung steht: «Oh! our dear fathers!»

${ }^{39}$ In der englischen Fassung folgt hier noch die typisch äthiopische Wiederholung «Very much how are you?», die Flad hier offenbar weggelassen hat.

${ }^{40}$ Dieser Satz interpretiert mehr als die englische Übersetzung, die näher am Original zu bleiben scheint: «but now since you sent us teachers, we have disputed very much; but we arrived at the truth».

${ }^{41}$ Jes 9:1 (wie Matth 4:16).

${ }^{42}$ Psalm 51:13.

43 Jes 53:2.

${ }^{44}$ Auch hier variiert die englische Fassung leicht, wohl dem amharischen Original folgend: «Glory be to the Father, glory be to the Son, glory be to the Holy Ghost, Amen». 


\section{Däbtära Bərru Wəbe [«Debtera Berru» $\left.{ }^{45}\right]$ an Johann Ludwig Krapf in Kornthal \\ [Gafat], ${ }^{46}$ [November/Dezember] 1864}

Im Namen des Vaters, des Sohnes und des heiligen Geistes, ein Gott. Dieser Brief des Debtera Berru, der Wolda Paulus ${ }^{47}$ heißt, gelange an Herrn Krapf, der unter den Heiden im östlichen Afrika Missionar gewesen ist. Wie geht es Ihnen? Ich bin wohl durch Gottes Güte. Ich kannte Sie früher nicht, aber nun hat mir Herr Flad Ihre Geschichte mitgetheilt. Daher frage ich nach Ihnen, nach der Liebe, welche zwischen Christen besteht. Früher, als ich noch Jude war, saß ich in der Finsterniß, nun aber bin ich durch die Liebe Gottes und Christi Gnade zum wahrhaftigen Glauben gelangt. ${ }^{48}$ Der heilige Paulus

\footnotetext{
${ }^{45}$ «...eines bekehrten Juden», ebenda. Zu seiner Biographie siehe QUIRIN, JAMES, «Bərru Wəbe», in: EAE I, 545.

${ }^{46}$ Flad schreibt im Dezember 1864 (Mittheilungen, Nr. 3, September 1865, 20), die Proselyten seien ihm nach Gafat gefolgt. Es ist anzunehmen, dass däbtära Bərru den Brief etwa gleichzeitig wie Flad verfasst hat; er nimmt indirekt auf Flad Bezug.

${ }^{47}$ Dies ist die Angabe des Taufnamens von Bərru; nach traditionell abessinischer Sitte ist der Taufname verschieden vom in der Öffentlichkeit getragenen Namen. Er wird oft sogar keinem außer dem Täufling und seiner engsten Familie bekannt (dazu siehe das Buch von lij Asfa-Wossen Asserate: Die Geschichte von Šawā (Äthiopien) 1700-1865 nach dem Tārika Nagaśt des Belāttēn Gētā Heruy Walda Śellāsē, Wiesbaden 1980 [Studien zur Kulturkunde, 53], 3, Fußnote 10). Der Taufname enthält hier die Anspielung auf Paulus, der seinen Namen bei seiner Konversion ebenfalls geändert hatte (ähnlich wie später der Oromo-Missionszögling Ruufoo, der ebenfalls «Paulus» als einen seiner Namen erhielt, oder die Oromo-Konvertitin «Pauline» Fathme, vgl. SMIDT, WolberT, «Quellenübersicht zur Biographie des ehemaligen Sklaven und ersten Oromo-Bibelübersetzers Christian Rufo», Afrikanistische Arbeitspapiere 67, 2001, 181-198.

${ }^{48}$ Er war bereits zu einem frühen Zeitpunkt konvertiert (1862, vgl. Bemerkung zu vorigem Brief): «Dieser war der erste bedeutende Bekehrte aus den Falaschas und hatte in all den schweren Jahren der Gefangenschaft sich als treuer Jünger Christi bewiesen». (FLAD, Michael Argawi. Ein mutiger Bekenner, 19). Über seinen Übertritt zum Christentum heißt es in der Biographie Flads: «Einer der angesehensten und gelehrtesten Falaschas, der Schriftgelehrte Debtera Beru (...), trat an einem Samstag in dem jüdischen Bethaus der Falaschas öffentlich auf und bekannte seinen neuen Glauben an Christus als Gottes Sohn und Erlöser der Welt [1862]. Er begründete danach seinen Glauben mit Stellen aus dem Alten Testament. Einundzwanzig andere Falaschas schlossen sich bald an und bekannten vor ihren ehemaligen Glaubensgenossen und ihren Vätern und Brüdern ihren Glauben an Jesus Christus. Dadurch entstand eine gewaltige Aufregung und Bewegung unter den Falaschas. Die Betreffenden wurden nicht nur von den Mönchen mit dem gefürchteten Bannfluch belegt, sondern auch von den nächsten Angehörigen verflucht». (FLAD, Johann Martin Flad. Ein Leben für Äthiopien, 35; ähnlich in FLAD, 60 Jahre in der Mission, 117). — 1874 wurde er Mitarbeiter der neugegründeten Falascha-Mission in der Missionsstation
} 
sagt: Gaben und Beruf mögen Gott nicht gereuen; ${ }^{49}$ aber er sagt auch: wie sollen sie glauben, was sie nicht gehört haben, oder wie sollen sie hören ohne Lehrer, denn der Glaube kommt durch's Hören, und das Hören kommt von Gott. ${ }^{50}$ Durch's Hören bin ich glaubig geworden. ${ }^{51}$ Dem Herrn sei Dank dafür, daß ER an uns gedacht hat nach seiner Güte, aber beten Sie für uns, daß, nachdem Gott uns vergeben und durch Christi Blut uns von Sünden gereinigt hat, wir nicht durch die vielen Versuchungen der Welt in das weltliche Wesen zurückgehen. Gott wolle seinen Heiligen Geist in unsern Herzen walten lassen, daß wir seinem Willen gehorsam seien und in der Wahrheit fest und zuverlässig werden; denn der heilige Johannes sagt: Welche an seinen Namen glauben, sind nicht von dem Geblüt, noch von dem Willen des Fleisches. ${ }^{52}$ Jedoch werden wir nicht gerecht durch unser eigenes Verdienst, ${ }^{53}$ sondern durch Christi Gnade und Barmherzigkeit; denn der Prophet Daniel spricht: O Herr, wir bitten Dich nicht wegen unsrer Gerechtigkeit, sondern wegen Deines großen Erbarmens. ${ }^{54}$ Unser Herr Jesus sagt: Das ist's, was ich euch gebiete, daß ihr euch unter einander liebet; ${ }^{55}$ deßhalb vergessen Sie uns nicht im Gebet, denn Paulus sagt: Sorget nichts, alles euer Anliegen mit Gebet und Flehen und Danksagen lasset kund werden vor Gott, so wird der allen Verstand übersteigende Friede Gottes mit euch sein. ${ }^{56}$ Die Gnade unsers Herrn

Ğända, wo die in St. Chrischona ausgebildeten Evangelisten Arägawi und Sänbätu Dané el die Mission wiederaufnahmen; «er bedeutete für die jungen Brüder geistlichen Rückhalt und Unterstützung». (FLAD, Michael Argawi. Ein mutiger Bekenner, 19). Weitere Details zu seiner Biographie siehe FLAD, 60 Jahre in der Mission, $387-$ 404.

${ }^{49} \mathrm{Vgl}$. 1. Korinther 12:4-5: «Es sind mancherlei Gaben; aber es ist ein Geist. Und es sind mancherlei Ämter; aber es ist ein Herr». 1. Korinther 12:4:7: «In einem jeglichen erzeigen sich die Gaben des Geistes zum gemeinen Nutzen».

${ }^{50}$ Leicht abgewandelte Bibelzitate, Römer 10:14: «Wie sollen sie aber an den glauben, von dem sie nichts gehört haben? Wie sollen sie aber hören ohne Lehrer?» Römer 10:17: «Der Glaube kommt durch's Hören, das Hören aber kommt durch Gottes Wort».

${ }^{51}$ Ist das eine versteckte Bitte um das Entsenden von mehr Lehrern?

${ }^{52}$ Joh 1:12-13: «Wie viele ihn aber aufnahmen, denen gab er Macht, Gottes Kinder zu werden, die an seinen Namen glauben; welche nicht von dem Geblüt noch von dem Willen des Fleisches noch von dem Willen eines Mannes, sondern von Gott geboren sind».

${ }^{53}$ Ein echt protestantisches Bekenntnis!

${ }^{54}$ Dan 9:18: «...nicht im Vertrauen auf unsere gerechten Taten legen wir dir unsere Bitten vor, sondern im Vertrauen auf deine große Barmherzigkeit».

${ }^{55}$ Joh 15:17: «Das gebiete ich euch, daß ihr euch untereinander liebet». (Wie Joh 15:12; Joh 13:34).

${ }^{56}$ Philipper 4:6-7: «Sorget nichts! sondern in allen Dingen lasst eure Bitten im Gebet und Flehen mit Danksagung vor Gott kund werden. Und der Friede Gottes, welcher höher ist denn alle Vernunft, bewahre eure Herzen und Sinne in Christo Jesu!» 
Jesu Christi, die Liebe Gottes und die Gemeinschaft des heiligen Geistes sei mit Ihnen. Amen.

Gedruckt in Mittheilungen, Nr. 3, September 1865, $20 \mathrm{f}$.

\section{Arägawi ${ }^{57}$ [«Aragau»] [vielleicht an Johann Ludwig Krapf, Kornthal] Gafat, 20. Januar 1865}

Im vergangenen Jahr wurde mein lieber B. Paulus, nachdem er sehr schwer krank gewesen, vom Herrn abgerufen, aber trauern Sie deßhalb nicht, denn unser Herr Jesus Christus spricht: Ich bin die Auferstehung und das Leben, wer an mich glaubt, der wird leben, ob er gleich stürbe..$^{58} \mathrm{Ja}$, sein Erlöser lebt und Er wird ihn hernach aus der Erde auferwecken. Er wird mit seiner Haut umgeben. Gott hat's genommen, der Name des Herrn sei gelobt! Wir waren Alle traurig, aber wir haben eine Verheißung, nemlich daß unser Herr Christus die Auferstehung und das Leben ist.

${ }^{57}$ Dieser Missionszögling stammte nach seiner Biographie, siehe FLAD, Michael Argawi. Ein mutiger Bekenner, aus einer Falascha-Familie, jedoch war schon sein Vater Christ. Später vielfach genannt als «Mika ${ }^{2}$ el Arägawi» (deutsch «Michael Argawi», oder «Michael Aragau»), was oft für Vor- und Vatersname gehalten wurde. Jedoch war Mika ${ }^{3}$ el sein Taufname, der in der abessinischen Tradition meist verborgen bleibt; Arägawi ist sein eigentlicher Name. Vgl. dazu der Brief von Flad aus Messina, 4. Juli 1866, der kurz nach seiner Ankunft auf seiner diplomatischen Mission zur Königin von England geschrieben worden war; er hat Arägawi mitgebracht (Mittheilungen, Nr. 2, September 1866, 10). Arägawi soll nach seinem eigenen Wunsch in St. Chrischona ausgebildet werden. Von diesem Wunsch hatte Flad bereits im Dezember 1864 in einem Brief berichtet (Mittheilungen, Nr. 3, September 1865, 20). Arägawi begleitete 1866 seinen Pflegevater Martin Flad, als dieser von Tewodros II. als Emissär zu Königin Viktoria gesandt wurde, bis Marseille; während Flad nach London weiterreiste, kam Arägawi von dort aus zum Missionsbegründer Friedrich Christian Spittler nach Basel und dann als Schüler in die Waisenanstalt in Weinheim bei Heidelberg; ab 1869 wurde er in der Pilgermission St. Chrischona bei Basel zum Missionar ausgebildet (siehe Pl. VIII). Mit drei weiteren konvertierten «Falascha», früheren Schülern von Flads Missionsschule in Ğända und nun ebenfalls auf St. Chrischona, wurde Arägawi 1873 als Missionar mit Martin Flad nach Ğända entsandt, um dort die Mission fortzuführen. Nachdem er lange als «Feldleiter» der Mission fungierte, wurde er 1894 als Nachfolger Flads zum Leiter der gesamten Falascha-Mission ernannt und erst 1925 nach 52 Dienstjahren von Willy Heintze, Ehemann von Flads Enkelin Eleonora Flad, in Ğända abgelöst (dazu siehe insbesondere Arägawis Biographie, FlaD, Michael Argawi. Ein mutiger Bekenner).

${ }^{58}$ Bibelzitat, Joh 11:25: «Ich bin die Auferstehung und das Leben. Wer an mich glaubet, der wird leben, ob er gleich stürbe». 
Als ich geboren wurde, verließ mich mein Vater und gieng nach Jerusalem, wo er sieben Jahre blieb. Nachher kam er mit Herrn Flad und den übrigen Europäern hieher ${ }^{59}$ und ich auch zu ihnen. Damals dachte ich, weil ich vorher nie weiße Leute gesehen, sie werden mich fressen, ${ }^{60}$ und fürchtete mich sehr; aber sie thaten mir anstatt Böses Gutes, sie lehrten mich den Weg des Lebens, ${ }^{61}$ welches mich sehr freute. Dieses Vertrauen und diese Liebe zu den Europäern wurde noch mehr gefördert durch Ihren 1[ieben] Brief, welcher mich sehr freute, sowie auch Ihr 1[iebes] Bild, ${ }^{62}$ welches Sie schickten. Ich danke Ihnen vielmal dafür, sowie für alle die übrigen Sachen, die Sie für uns schickten.

Beten Sie für mich, denn ich wohne unter einem bösen Volk, und mein Herz ist so böse, damit Gott mich zu einem neuen Menschen und Kind Gottes macht.

Ich lerne jetzt deutsch schreiben, ${ }^{63}$ und ich hoffe Ihnen recht viele Briefe zu schreiben in Zukunft; unterdessen verzeihen Sie die Fehler, die ich mache. ${ }^{64}$ Grüßen Sie alle Ihre Freunde, die uns schwarze Abessinier lieb

${ }^{59}$ Diese kamen 1856 aus Jerusalem in Abessinien an, offenbar in Begleitung des (namentlich nirgendwo genannten) Vaters; daraus ergibt sich das exakte Geburtsjahr von Arägawi, das bisher unsicher war: 1849, da der Vater sieben Jahre nach der Geburt in Jerusalem lebte. Zur Zeit dieses Briefes ist er also fast 16 Jahre alt.

${ }^{60}$ Das Motiv des Kannibalismus ist bei zahlreichen afrikanischen Völkern weit verbreitet, wenn diese Angehörige fremder Völker beschreiben.

${ }^{61}$ Bezug auf Joh 14:6: «Ich bin der Weg und die Wahrheit und das Leben; niemand kommt zum Vater denn durch mich». Vgl. auch Sprüche 15:24: «Der Weg des Lebens geht überwärts für die Klugen, auf daß er meide die Hölle unterwärts».

${ }^{62}$ Die erste Erwähnung von Fotografie in Briefen aus Äthiopien.

${ }^{63}$ Er arbeitete in dieser Zeit auch bereits als Hilfsübersetzer bei den Missionaren; die Missionare «beschäftigen sich mit allerlei schriftstellerischen Arbeiten ... In ihren Uebersetzungen unterstützt sie besonders der Christ Jakob Aragau, welcher später auf St. Chrischona aufgenommen zu werden wünscht». (CHRISTIAN FRIEDRICH SPITTLER, Siebzehntes Rundschreiben an die Freunde der Pilgermission, Basel, Dezember $1865,18)$. Der Name «Jakob» taucht sonst nirgendwo auf, vermutlich handelt es sich daher hier um einen Fehler oder um den ansonsten unbekannten Vatersnamen (siehe Fußnote 59).

${ }^{64}$ Diese Passage zeigt, dass dieser Brief auch im Original auf Deutsch verfasst ist; die Fehler jedoch sind korrigiert (und zwar in Basel; «ich danke Ihnen vielmal» ist eine typisch schweizerische Formel, auf Hochdeutsch wäre es «vielmals»). Auch der Stil des Briefes weicht ganz von dem üblichen äthiopischen Briefstil ab; er zeigt den deutschen Einfluss sehr deutlich. Arägawi wuchs seit seinem achten Lebensjahr bei den Europäern auf und wurde Flads Pflegesohn in Ğənda, bis dieser 1864 von dort vertrieben wurde und mit seiner Familie nach Gafat kam. Wegen enttäuschter 
haben und uns Gutes thun, und sagen Sie ihnen, daß ich mich sehr freuen werde, sie alle im Himmel einmal zu sehen und für ihre Liebe ihnen danken zu dürfen. - Die Gnade unseres Herrn Jesu sei mit Ihnen und Ihrem dankbaren

Aragau.

Gedruckt in Mittheilungen, Nr. 1, Juni 1866, 1f.

Erwartungen an die englische Regierung hatte Tewodros II. zunächst im November 1863 die neuangekommenen englischen Judenmissionare Stern und Rosenthal in Gondär gefangengenommen; die übrigen Missionare, denen nun Beschimpfung des Königs (z. B. in ihrer Korrespondenz) vorgeworfen wurde, wurden seither auch als Gefangene betrachtet, konnten sich aber zunächst noch frei bewegen. Im Januar 1864 wurden der englische Konsul Cameron und sechs der Missionare, unter ihnen Flad, ebenfalls in Ketten gelegt und dann auch ihre Familien gefangengenommen. Im Februar wurden diese sechs nach Gafat entlassen, zwar bewacht, wo sie aber ihre Arbeit wiederaufnehmen konnten (die Missionsstation Ğənda blieb aber seither verwaist); Staiger und Brandeis setzten auch den Unterricht wieder fort. Trotz ihrer Bewachung gelang es, mehrere Briefe nach Massawa und in die Grenzstadt Mätämma zu schmuggeln, wodurch die Nachricht von ihrer Gefangennahme nach Europa drang. Seither verschlechterte sich die Situation der Missionare graduell immer mehr, bis sie schließlich 1867 alle in auf der Bergfeste Mäqdäla in Ketten gefangengelegt wurden. Die Intervention der britisch-indischen Armee führte zu Ostern 1868 zur Befreiung aller Gefangenen (vgl. FLAD, Johann Martin Flad. Ein Leben für Äthiopien, 36ff.). 
8. Moritz Hall [«M. Hall» ${ }^{65}$ an Bischof Samuel Gobat ${ }^{66}$ in Jerusalem [Gafat], 2. Januar 1866

«Ich bin ein Israelit, von Polen gebürtig. ${ }^{67}$ Nach vielen Irrfahrten kam ich endlich nach Abyssinien, wo ich Ihre Missionare, die Herren Bender, Meyer, Waldmeyer, Kienzlen und Saalmüller kennengelernt habe, und von ihnen gelehrt worden bin, daß Jesus der Messias, der Heiland der Sünder und mein Heiland ist. Durch diesen Glauben habe ich Frieden für meine Seele und die Vergebung meiner Sünden gefunden. Die lieben Brüder haben mich in ihre

${ }^{65}$ Kanonengießer von Tewodros II., Ehemann einer Äthiopierin und Begründer einer bedeutenden deutsch-äthiopischen Familie, von der mehrere Mitglieder nach langem Aufenthalt in Palästina (nach 1868) seit etwa 1903 in Äthiopien z. T. wichtige Positionen an den Höfen der Kaiser Mənilək II. und Haylä Səllase I. sowie von lo ul ras Asratä Maryam Kasa, Gouverneur von Eritrea, einnahmen. Wegen der engen Verbindung dieser Familie mit der äthiopischen Geschichte wurde auch dieser Brief eines Nicht-Äthiopiers, der den Anfangspunkt dieser Geschichte darstellt, aufgenommen. - Kürzlich ist eine kurze, dreisprachige Biographie von ihm erschienen (Deutsch, Englisch, Hebräisch): Holtz, Avraham - Holtz, Toby Berger, Moritz Hall: Der alte Mann von Jaffa. The Old Man of Jaffa, Haifa 2003 (Abhandlungen des Gottlieb-Schumacher-Instituts / Publications of the Gottlieb Schumacher Institute, 3). Darin werden die bisher bekannten Dokumente und Berichte zu seinem Leben ausgewertet, ausgehend von einer kurzen farbigen Schilderung des «alten Mannes von Jaffa» (Moritz Hall) in einem Roman des Nobelpreisträgers Agnon. - In Äthiopien heiratete Hall die junge Wälättä Iyäsus «Housepian», deren christlicher Taufname Cathérine bzw. Katharina lautete (katholisch getauft durch den oben bereits genannten Missionar Justin de Jacobis), Tochter eines deutschen Einwanderers und einer früheren äthiopischen Hofdame und ihrerseits später eine einflussreiche Hofdame am Hof von Kaiserin TTaytu (zu deren Herkunft u. a. SMIDT, WolberT, «Verbindungen der Familie Ustinov nach Äthiopien», Aethiopica. International Journal of Ethiopian and Eritrean Studies 8, 2005, 30-49). Moritz Hall war Äthiopiern offenbar nur unter seinem Vornamen bekannt (vgl. der unten genannte Brief von Tewodros II.), was sich auch an europäischen Berichten zeigt, die ihn «Herrn Moritz» nennen (vgl. u. a. Holtz - Holtz, Moritz. Hall: Der alte Mann von Jaffa, S. 34, Fußnote 39; Evgenia Sokolinskaia, «From Qwara to Mäqdäla. Index of Proper Names from the Three Chronicles of Emperor Tewodros II's Reign», in: Böll, VerenA — Nosnitsin, Denis - Rave, Thomas - Smidt, Wolbert - Sokolinskaia, Evgenia (eds.), Studia Aethiopica. In Honour of Siegbert Uhlig on the Occasion of his 65th Birthday, Wiesbaden 2004, 269-290, hier 280, 284).

${ }^{66}$ Bischof der Anglikanischen Kirche in Jerusalem und Leiter der Mission in Äthiopien.

${ }^{67}$ Geboren am 14. März 1838 in Krakau (gem. Dokumenten im Besitz von Jochen Bertsch in Stuttgart, dem ich an dieser Stelle für seine Großzügigkeit danke, mit der er mir Zugang zu Familienpapieren Hall verschafft hat). 


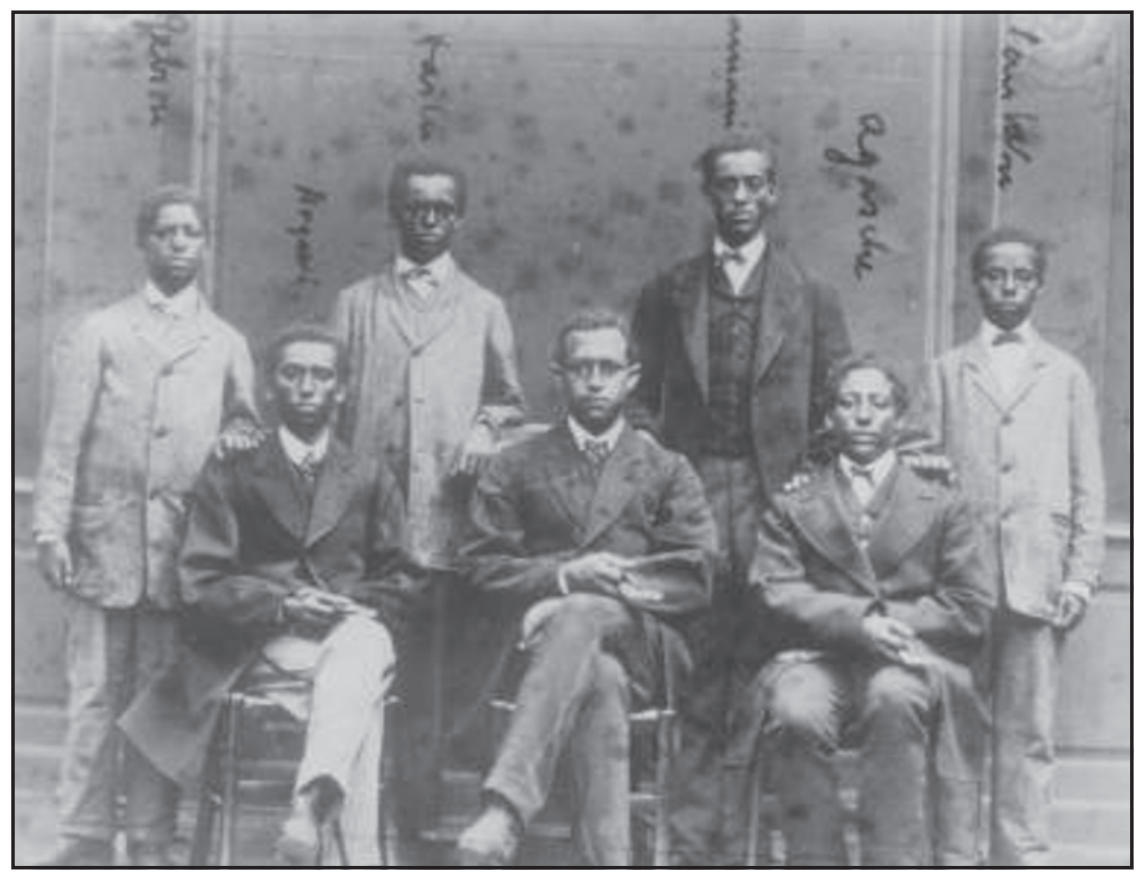

Pl. vIII. Mika ${ }^{\top}$ el Arägawi (sitzend vorne links) um 1871 als Schüler in St. Chrischona, zusammen mit den anderen später angekommenen äthiopischen Schülern, von links nach rechts:

Gobbaw Dästa (später bekannt als Gäbru Dästa), Haylu Wäsän, Gngədasät alias Wilhelm Schimper, Sämªnni Danəel, Agaže Sahlu, Sänbätu Danəºl, aus Privatbesitz Frau Johanson-Flad 
Gemeinschaft aufgenommen, ${ }^{68}$ und ich darf an ihren Gottesdiensten und an-

${ }^{68}$ Die Frage, wann genau Moritz Hall in die Gemeinschaft aufgenommen wurde, war bisher nicht endgültig geklärt (Holtz — Holtz, Moritz. Hall: Der alte Mann von Jaffa, 30f.). Die Abschrift seiner Hochzeitsbescheinigung von C. F. W. Flad, «Direktor der Fladschen Mission in Abessinien» in St. Légier bei Vevey am Genfer See, vom 6. Oktober 1937 (im Besitz von Jochen Bertsch, Stuttgart), besagt, dass er am 17. Mai 1863 in Gondär «Evangelisch getraut worden ist von dem von der Pilgermission St. Chrischona bei Basel entsandten Missionar Saalmüller». Das zeigt, dass er bereits zu diesem Zeitpunkt den Missionaren nahestand (seine junge Frau war Missionszögling). Ein undatierter Brief von Tewodros II. an die europäische Gemeinde von Gafat, verfasst nach Januar 1862, aber offenbar vor dem August 1862 (den WALDMEIER, The Autobiography of Theophilus Waldmeier, 21-24, veröffentlichte, vgl. Rubenson, Tewodros and his Contemporaries, 189), richtet sich an die Herren «Kienzlen, Waldmeier, Saalmüller, Moritz [sic!], Bender und Bourgaud». Aus dem Kontext von Waldmeiers Bericht, in den der Brief eingebettet ist, geht hervor, dass die Europäer bereits begonnen hatten, Kanonen zu gießen. Aus verschiedenen Erwähnungen von Moritz Hall ist bekannt, dass dieser als ehemaliger Soldat der russischen Armee das Gießerhandwerk gelernt hatte (HoLTz — HolTz, Moritz. Hall: Der alte Mann von Jaffa, 12f., 30), somit als einziger Europäer für Tewodros' Auftrag praktische Erfahrungen aufweisen konnte und dann an der Fabrikation von Kanonen und zwei größen Mörsern mitwirkte (ein Dokument von Missionar Saalmüller, also aus erster Hand, bestätigt und präzisiert die bisher bekannten Berichte über seine Rolle als Kanonengießer des Herrschers: Auf der Rückseite einer Originalzeichnung des Anfang 1868 hergestellten Mörsers «Sebastopol» befindet sich folgende Widmung an einen der Söhne Halls: «Au cher Frédéric Hall en souvenir du mortier fabriqué par Messieurs Waldmeier, Saalmüller et Hall 1868. M. Saalmüller»). — Er ist also jedenfalls vor Mitte 1862 in die Gemeinschaft der Missionare aufgenommen worden. In einem weiteren Dokument von C. F. W. Flad, ebenfalls vom 6. Oktober 1937, wird das Jahr 1862 als Aufnahmejahr ausdrücklich genannt: «Es wird hiermit beglaubigt, dass Herr Moritz Hall während seines Aufenthaltes in Abessinien in den Jahren 1862-1868 mit den Missionaren der Basler St. Chrischona Mission zusammengelebt und gewirkt hat zur Zufriedenheit des damaligen Königs Theodros, der ihn auch mehrfach ausgezeichnet hat». (Beide Dokumente im Besitz von Jochen Bertsch, Stuttgart). Das Jahr 1862 muss allerdings nicht das Jahr seiner Konversion sein; wir wissen, dass die Pilgermissionare großen Wert auf eine echte «innere» Bekehrung legten und Taufwilligen zunächst längeren Unterricht erteilten (wie z.B. bei afrikanischen Zöglingen belegt, vgl. SMIDT, «Quellenübersicht zur Biographie des ehemaligen Sklaven»). — Hall dürfte aber spätestens zum Zeitpunkt seiner christlichen Hochzeit 1863 Christ geworden sein. In der Familie des Hall-Sohnes David in Addis Abeba hieß es dagegen, Moritz Hall sei «wohl» 1865 konvertiert; eine Hall-Tochter berichtete außerdem, er habe sich erst in Gefangenschaft in Mäqdäla taufen lassen (Holtz - Holtz, Moritz Hall: Der alte Mann von Jaffa, 29), was aber schon der hier abgedruckte Brief widerlegt, da die Gefangenschaft in Mäqdäla erst 1867 begann. 
dern religiösen Übungen Theil nehmen, ${ }^{69}$ was meiner Seele zur Stärkung und zum Segen gereicht. Der Gott aller Gnade wolle Sie tausendfältig segnen für das Werk der Mission, das Sie in Abyssinien gegründet haben, ein Werk, das schon viele bekannte und unbekannte Früchte getragen hat. Gedenken Sie unser in Ihren Gebeten, wie wir es hier auch täglich für Sie thun.

M. Hall.»

Gedruckt in «Bischof Samuel Gobats Sendschreiben an die Brüder in der Heimath (Schluß)», Christlicher Volksbote 2, 9. Januar 1867, 9-12, hier 9. ${ }^{70}$

${ }^{69}$ Diese Briefstelle zeigt deutlich, dass Hall nicht selbst als Missionar tätig war, wie es eigentlich in der Überlieferung der Nachfahren hieß (z.B. bei den Halls in Äthiopien, siehe CRUMMEY, Priests and Politicians, 132, sowie bei der deutschenglischen Familie von Ustinov - vgl. Sir Peter Ustinov, der über den Vater seiner Großmutter sagt, dass er «... als Missionar in Äthiopien wirkte. Als Schweizer [der er nicht war, aber er arbeitete ja mit einer Schweizer Mission] war er offenbar kein unbegabter Ingenieur und baute - neben seinen anderweitigen religiösen Pflichten - für den verrückten Kaiser Theodor eine Kanone, woraufhin ihn dieser an seine eigene Erfindung ketten ließ, damit er sich nicht aus dem Staub machen und jedem anderen ebenfalls eine Kanone bauen konnte...», Ustinov, Peter, Ich und Ich. Erinnerungen, Düsseldorf - Wien — New York 1992, [3. Aufl.], 17). Als Mitglied der Handwerkerkolonie Gafat war Hall aber tatsächlich Missionsmitarbeiter, und blieb dies auch in späteren Jahren als prominentes Mitglied der Deutschen Kolonie in Jaffa, Palästina, was die Familienüberlieferung erklärt. Acton schreibt: «...they were joined in time by others who were not missionaries, such as Moritz, a Polish deserter from the Russian army, Bourgaud, a French gunsmith...» etc. (Acton, Roger, The Abyssinian Expedition and The Life And Reign of King Theodore With One Hundred Illustrations ... of the Illustrated London News, London 1868, 18f.).

${ }^{70}$ Ich verdanke Dr. Toby Berger Holtz den Hinweis auf diesen Brief und danke ihr an dieser Stelle sehr herzlich für ihre große Hilfsbereitschaft und Interesse (vgl. Holtz - Holtz, Moritz. Hall: Der alte Mann von Jaffa, 31, Fußnote 29). 


\section{As se Tewodros II. [«Theodoros»] an Martin Flad in Massawa ${ }^{71}$}

\section{Januar 1867 [per Boten gesandt am 14. Januar 1867² ]}

Im Namen des Vaters, des Sohnes und des heiligen Geistes, Ein Gott.

Dieser Brief, der gesandt ist von dem König der Könige, Theodoros, gelange an Herrn Flad. Wie befindest Du Dich? Ich bin gottlob wohl.

Am 29. Dez. sind Deine drei Boten bei mir angekommen. Sage jenen Leuten, die mit Dir kamen und welche Leute meiner Freundin, der Königin von England, sind, und Colonel Merewether, ${ }^{73}$ wie befindet Ihr Euch? Herr Rassam, Herr Cameron ${ }^{74}$ samt den übrigen sind durch Gottes Kraft wohl.

${ }^{71}$ Flad war 1866 von Tewodros II. auf Gesandtschaft zu Königin Victoria gesandt worden (wobei seine Frau und Kinder als Geiseln zurückblieben), um von ihr die Entsendung von Handwerkern nach Äthiopien zu erwirken — als Bedingung für die Freilassung der von ihm festgehaltenen, teilweise in englischen Diensten stehenden Europäer. Am 8. Oktober 1866 verließ Flad nach einer Audienz bei Victoria mit einem eigenhändigen Brief der Königin London und war bereits am 29. Oktober in Massawa (FlaD, 60 Jahre in der Mission, 190, dort auch Zusammenfassung des Briefes). Die Geschenke für Tewodros sowie die Handwerker kamen etwas später nach; Flad übersetzte in dieser Zeit den Brief ins Amharische und sandte ihn durch Boten an den König der Könige nach Däbrä Tabor. Am 13. Januar 1867 fand dort eine «große Beratung» (so ein Brief von Staiger in Gafat an Flad in Massawa, siehe FLAD, 60 Jahre in der Mission, 193) statt, deren Ergebnis der oben zitierte Brief von Tewodros ist: «Der König ließ in großer Aufregung einen Brief an Dich schreiben. Die Freundschaft mit England ist zu Ende. Er will weder Arbeiter noch Waren. Alles was du bringst, sei ihm angenehm, sei es Krieg oder Frieden, nur sollst Du bald kommen. Morgen gehen die Boten an Dich ab. ... Der König ist entschieden, nicht nachzugeben, sondern im Gegenteil Trotz zu bieten, und zwar erstens, weil er glaubt, im Recht zu sein, und zweitens, weil er sehr zweifelt, daß England Gewalt gegen ihn brauchen kann und brauchen wird». (ibid., 193f.)

72 So die Nachricht von Staiger an Flad (FlaD, 60 Jahre in der Mission, 193); Flad erhielt Mitte Februar 1867 in Massawa die Nachricht von seiner Frau, Pauline Flad, Tewodros habe einen Brief über Mätämma an ihn gesandt, worauf er am 6. März 1867 über Bogos und Kassala Richtung Mätämma abreiste; den Brief erhielt er, als er bei «Zaga» im Barka-Land die königlichen Boten traf (ibid., 198).

${ }^{73}$ General Merewether kam im Dezember 1866 mit den von Tewodros II. für Äthiopien geforderten englischen Handwerkern und Geschenken für den Herrscher in Massawa an. Königin Victoria von England hatte an deren Weitersendung an Tewodros die Bedingung geknüpft, dass er zuvor Konsul Cameron, den Gesandten Rassam und die Missionare freilasse (FLAD, 60 Jahre in der Mission, 197).

${ }^{74}$ Hormuzd Rassam, eigentlich ein britisch-armenischer Archäologe, nun First Assistant des Britisch-Indischen Gouverneurs von Aden, war der britische Gesandte, der 1864 zu Verhandlungen über die Freilassung Konsul Camerons und der gefangenen Missionare zu Tewodros II. entsandt worden war. Er reiste nach 15monatigem Briefwechsel im Oktober 1865 zu Tewodros, wurde aber nach baldiger Freilassung 
Herr Rassam sendet durch seinen Diener ${ }^{75}$ einen Brief. Wir warten auf Euer aller Ankunft. Ich, ein armer Mann, warte auf den Willen meiner Freundin, der großen Königin von England und Irland, ${ }^{76}$ welche eine Freundin des Glaubens und der Freundschaft ist.

Aus diesem Grunde behalte ich Herrn Rassam hier. ${ }^{77}$ Wenn ihre Majestät mir ein Freundschaftszeichen sendet, so bringe mirs, und wenn ich es gese-

aller Europäer kurz darauf selbst mit allen anderen gefangengesetzt (1866). Cameron war seit 1861 der britische Gesandte in Abessinien (zu dessen Titel siehe Acton, The Abyssinian Expedition, S. 19), den Tewodros Anfang 1865 in Ketten gelegt hatte. Als Repräsentanten ihrer Regierung, mit der Tewodros in Konflikt liegt, werden sie hier an erster Stelle genannt.

${ }^{75}$ Worum es sich dabei handelt, ist unklar; der «Diener» ist wahrscheinlich der von Tewodros Rassam persönlich als baldäräba zugeteilte Samu'el Giyorgis, ein in seiner Jugend durch die Missionare Kruse und Isenberg getaufter Saho und nun Hofmann und Arabisch-Dolmetscher von Tewodros; seit 1866 ist es durch Briefe belegt, dass Samu ${ }^{2}$ l die Briefe zwischen Tewodros und Rassam als Bote besorgte (RUBENson, Tewodros and his Contemporaries, passim; zur Biographie von Samu'el vgl. Smidt, Wolbert, «Before Eritrea, Before the Diaspora: Habesha in Exile and on Missions Abroad in the 19th Century», Eritrean Studies Review 4-2, 2005, 1-36 (= CoNRAD, BETTINA - REDEKER HePNER, Tricia [eds.], Eritrea Abroad: Critical Perspectives on the Global Diaspora).

${ }^{76}$ In allen seinen Briefen lässt Tewodros den Titel der «Kaiserin von Indien» weg, eine nicht uninteressante Tatsache, die bisher in der Litaratur nie diskutiert wurde. Möglicherweise ein antikoloniales Moment?

77 Tewodros ging also auf die Bedingung der englischen Regierung nicht ein, die Gefangen zuvor freizulassen. Die englischen Handwerker, die bis jetzt in Imkullu bei Massawa gewartet hatten, wurden deshalb von Merewether wieder nach England zurückgesandt, nachdem der geschäftsführende englische Vize-Konsul Munzinger diesen Brief zu ihm gebracht hatte; Munzinger hatte mit seiner Frau (die bis Keren mitkam) von Massawa bis ins Barka-Land Flad auf dessen Reise nach Mätämma begleitet (FLAD, 60 Jahre in der Mission, 199). Es scheint aber hier eine gefährliche Zuspitzung in der Interpretation dieses Briefes — durch Flad, Munzinger und Merewether - stattgefunden zu haben: Diese Briefstelle kann nur in Zusammenhang mit Staigers oben zitiertem Brief als echte Ablehnung verstanden werden; es wäre aber offenbar richtiger, von Verzögerungstaktik auszugehen. Tatsächlich handelt es sich hier zwar um die Ablehnung von Bedingungen, aber nicht um einen Entschluss zum Krieg - Tewodros, wenn man die Formulierung in diesem Brief ernst nimmt, scheint «Freundschaft» zu erwarten und eine Beilegung des Konflikts; ein wichtiges kulturell geprägtes Verhandlungsmuster spielt hier eine Rolle: Das Stellen von Bedingungen (hier durch Victoria) wird eher als die Eröffnung von Verhandlungen verstanden, nicht als deren Schlusspunkt, als der sie hier von den Engländern gemeint waren. Die sofortige Rücksendung der Handwerker zeigt, wie unfähig die beteiligten Europäer waren, dieses Verhalten richtig zu werten bzw. bereit waren, darauf in irgendeiner Form einzugehen. - Gleich darauf begannen die Vorbereitungen der Invasion der britisch-indischen Armee unter Kommando des Generals Napier aus Bombay. 
hen habe, so will ich Herrn Rassam auf eine freundliche und ehrenvolle Weise senden.

Gedruckt in Johann Martin Flad, 60 Jahre in der Mission unter den Falaschas in Abessinien, Gießen - Basel 1922, 199. Englische Version ${ }^{78}$ in Acta Aethiopica II, no. 208: Rubenson, Tewodros and his Contemporaries, 316.

\section{Mälakä gännät ${ }^{79}$ Afä Wärq, aläqa Wäldä Mäsqäl, wäyzero Täwabäčč} an Friedrich Bender ${ }^{80}$ Johannes Mayer und ihre Familien [in ${ }^{\mathrm{c}} \mathrm{Adwa}{ }^{81}$ ] Lager in «Seraul», März/April $1869^{82}$

Dieser Brief, gesandt von Malaka Ganet Afa Work, von Alaka Wolda Maskal, von Frau Jawabatsch ${ }^{83}$ möge an die Herren Bender, Mayer und ihre Familien kommen. Wir fragen erstlich: Wie geht es Euch? Hat Euch das Land (oder die Stadt ${ }^{84}$ ) aufgenommen? Der Vater Jesu Christi behüte Euch und beschütze Euch! Wie Gott den heil. Aposteln Petrus und Paulus ihr Apostelamt gelingen ließ, so wolle Er auch Euch den Auftrag, den Er Euch gegeben hat, ausführen und gelingen lassen! Wenn Gott sich dieses Volkes erbarmt, wird Er Euch Eures Herzens Wunsch erfüllen und geben, daß Ihr unsern in der Finsterniß sitzenden Brüdern zum Licht des Evangeliums ${ }^{85}$ verhelfen werdet. Amen.

Gedruckt in Mittheilungen, Nr. 6, Dezember 1869, 23.

${ }^{78} \mathrm{Da}$ das Original bisher nicht auffindbar war, dürfte die deutsche Fassung von Interesse sein.

${ }^{79}$ Mälakä ( $\left.m \ddot{a} l{ }^{3} a k a ̈\right)$ gännät ist ein geistlicher Titel.

${ }^{80}$ Strebel, Barbara, «Bender, Christian Friedrich», in: EAE I, 527.

${ }^{81}$ Bender und Mayer sind am 1. März 1869 in ${ }^{\mathrm{c}}$ Adwa, der Hauptstadt des Herrschers von Təgray, Kasa, angekommen und begannen sofort mit dem auch nun hier lebenden aläqa Zännäb mit öffentlichen Bibelstunden, vgl. KRAPF, JoHANN LudwiG, Chrischona-Blättchen, Nr. 3, September 1869 (Staatsarchiv Basel-Stadt, Privatarchiv 653, D 1 - Organisation, 7.: Chrischona Blättchen 1869).

${ }^{82}$ Mayer und Bender erhielten diesen Brief von «Freunden» aus der Zeit in Mäqdälä in ${ }^{\mathrm{c} A d w a}$ am 8. April 1869 nach Mayers Tagebucheintrag, Mittheilungen, Nr. 6, Dezember 1869, 23.

${ }^{83}$ «Jawabatsch» ist wahrscheinlich verschrieben aus Tawabatsch (= Täwabäčč).

${ }^{84}$ Einfügung des Briefübersetzers Mayer.

${ }^{85}$ Bezug auf Matth 4:16. 


\section{Annex. Brief des Tewodros II. an Samuel Gobat}

Dieser Brief, gesiegelt von Tewodros II., scheint eine Abschrift jenes Briefes gewesen zu sein, welcher von Appleyard - Pankhurst, Letters from Ethiopian Rulers, 135-142 [no. xxvI], und Rubenson, Tewodros and his Contemporaries, 10f. [no. 5] veröffentlicht wurde. Wie die sehr saubere Ausfertigung und das Siegel zeigen, wurde diese Kopie möglicherweise gleich nach dem Schreiben des Originalbriefes von der gleichen Hand erstellt. Dass es eine Kopie ist, zeigt auch die Tatsache, dass das Siegel nicht wie bei Herrscherbriefen üblich über dem Brief, sondern unter dem Brief angebracht is ${ }^{86}$ (man kann hier also gewissermaßen von einer im äthiopischen Kontext durchaus ungewöhnlichen «beglaubigten Kopie» sprechen). Nachdem die Abschrift von Tewodros gesiegelt wurde, versah Johann Ludwig Krapf ihn mit einer englischen Bemerkung und der an eine ungenannte Person gerichteten Bitte um Überprüfung des Inhalts. Der von Appleyard und Rubenson veröffentlichte Brief ist mit einiger Sicherheit derjenige, auf den sich unsere oben abgedruckte alte deutsche Übersetzung bezieht, und der als offizielle Anfrage Tewodros II. an Bischof Samuel Gobat gesandt wurde. Krapfs Abschrift blieb jedoch bisher völlig unbekannt und war immer in Privatbesitz.

Die Bemerkung Krapfs zwischen Brief und Siegel lautet: «This is a copy of the accompanying letter for Bishop Gobat which we send you to see, that you may judge whether it is properly written JLK». Darunter folgt eine deutschsprachige Notiz in der selben Handschrift, allerdings rund sechs Jahre später angebracht: «Diesen amharischen Brief brachte ich im Jahr 1855 aus Abessinien — von König Theodoros Kornthal 1 August 1861 L Krapf». - Krapf scheint also 1861 den Brief an jemanden weitergegeben zu haben, vermutlich an ein Mitglied der St. Chrischona-Pilgermission bei Basel; nach Martin Flads Rückkehr aus Äthiopien 1868 kam der Brief in dessen Besitz.

Die englische Notiz Krapfs zeigt, dass Krapf vor der endgültigen Annahme des Briefes sichergehen wollte, dass die Interessen seines Missionsprojektes gewahrt bleiben; dies jedenfalls würde seine Bitte um Überprüfung des Inhalts erklären. Diese Überprüfung konnte allerdings nicht ohne persönliche Einwilligung von Tewodros II. durchgeführt werden. Die Verwendung der englischen Sprache deutet darauf hin, dass Krapfs Bitte an einen Engländer am Hof gerichtet war. Dies kann nur der enge Vertraute des Tewodros, John Bell, gewesen sein, der als Anglikaner selbst ein gewisses Interesse am Erfolg der protestantischen Mission gehabt haben mag.

${ }^{86}$ Der äthiopischer Historiker Märsə⿳亠丷厂 Hazän Wäldä Qirkos erwähnt die Tatsache, dass das Anbringen von Siegeln oben nuir bei Königsbriefen üblich war (Merc'é Haren Wolde Qirqos, Of what I Saw and Heard: the Last Years of Emperor Menelik II \& the Brief Rule of Iyassu, introduction by G. Prunier, tr., annot. by Hailu Habtu, Addis Ababa 2004 (Ethiopian Studies 1), 91). 


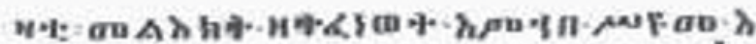

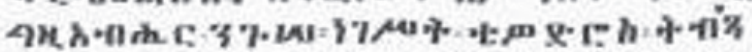
h.

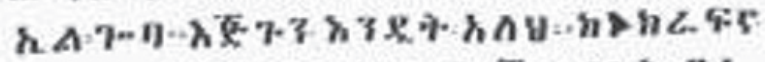
hovem. T:A Һร

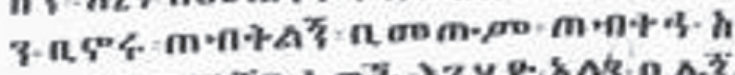

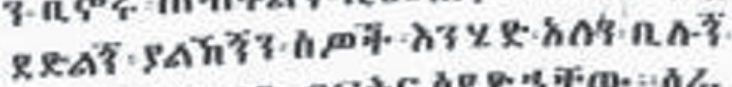

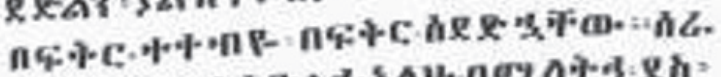

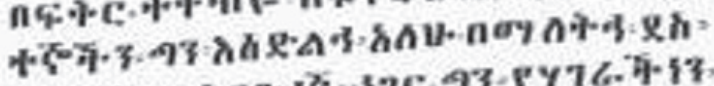

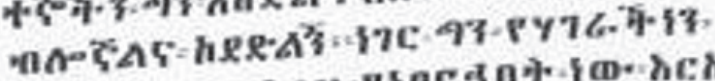
หาc

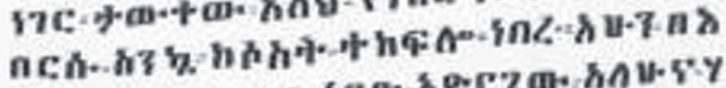

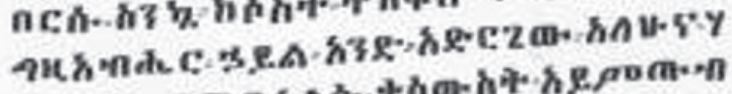
gav 5 + उ.

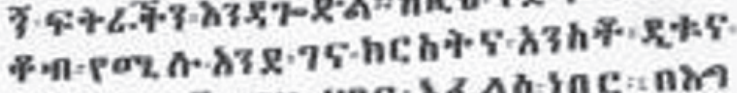

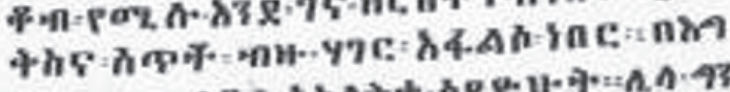

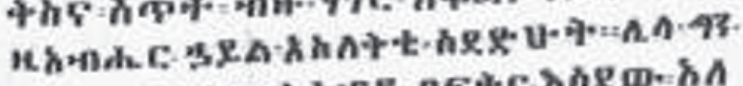
В

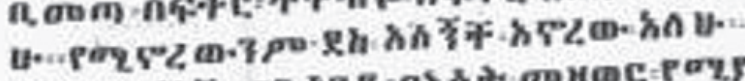
hou Ch-hร

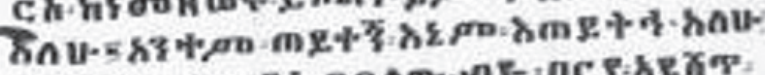

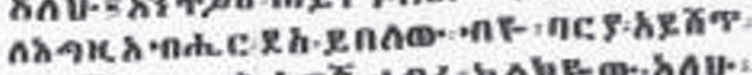

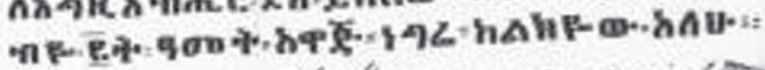

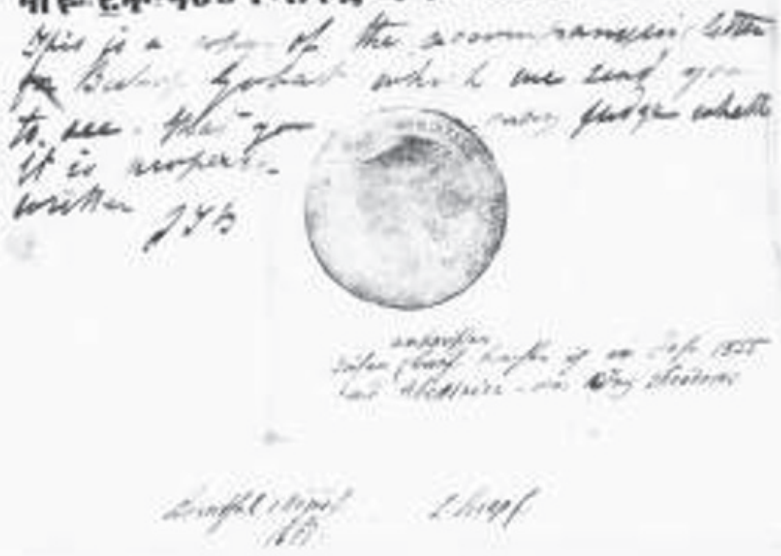

Pl. IX. Brief des Tewedros II. an Samuel Gobat 
Als Ergebnis des Vergleichs kann festgehalten werden, dass trotz Detaildifferenzen beide Texte praktisch identisch sind. Die Unterschiede zwischen Krapfs Abschrift und dem bereits publizierten Brief sehen im Detail folgendermaßen aus. In Krapfs Abschrift:

- 4. Zeile: kännäkərafənna (statt käkərafənna), ein Schreibfehler (das Wort, das sich auf die im Amharischen öfter verwendete Konstruktion bezieht, hätte bedeutet: «[von] Krapf und denjenigen, welche in seinem Gefolge [sind]» und wurde korrigiert);

— 12. Zeile: yänäbbärḩ̧əbbät (statt yänäbbärhəbbät), keine Sinnveränderung;

- 15. Zeile: yämmiyafalləsu (statt yämmifalləsu): Krapfs Abschrift korrigiert das Wort gemäß einem weiter unten im Text erscheinenden Satz (das könnte allerdings auch darauf hindeuten, dass der Kopist das Original vor Augen hatte). Hier gibt es eine gewisse Unklarheit, die vor allem deswegen entsteht, weil sich aus der Wurzel fälläsa mehrere ähnlich aussehende Verben mit unterschiedlicher Semantik bilden (vgl. täfalläsä 'to be in disorder', afälläsä 'to dig up; to uproot', afalläsä 'to disrupt' etc.: T. L. Kane, Amharic-English Dictionary, Wiesbaden 1990, vol. II, 2263-2264). Appleyard übersetzt unterschiedlich: «...do not any priests come against me who will dispute the Faith...», und «...one whom they call Abba Ya 'eqob had disrupted many regions...»; Rubenson übersetzt in gleicher Weise: «let no priests who disrupt the faith come to me»; «he who is called father De Jacobis disrupted many districts». Die zeitgenössische deutsche Übersetzung, welche oben abgedruckt ist, versucht sich näher an die genaue Wortbedeutung zu halten: «Priester welche den Glauben vertreiben (verstören) sollen nicht zu mir kommen», und «Früher hat der sogenannte Vater Jakob ... zu viele Dörfer zum Abfall bewogen». In allen Fällen sind die Aussagen aus dem Kontext ziemlich gut zu verstehen; jede Fehlinterpretation ist ausgeschlossen.

- 16. Zeile: əndagodəl (statt əndaygodəl) war ein Schreibfehler.

- 23. Zeile: in sämčä wurde der erste Buchstabe versehentlich ausgelassen, dann aber gleich über der Zeile geschrieben.

— 24. Zeile: stäyyəqəh̆ [allähu] (statt asțäyyəqəh̆ [allähu]), «Ich werde dich besuchen». Die Bedeutung dieser Bemerkung in dem von Appleyard und Rubenson veröffentlichten Text ist wörtlich: «Ich werde jemanden senden, Dich zu besuchen». Appleyard übersetzt: «Do you enquire of me and I shall have you enquired of»; Rubenson hat in seiner Übersetzung auch hier den Sinn richtig: «Keep in touch with me (lit. inquire about me) and I shall keep in touch with you». Dem entspricht weitgehend auch die oben abgedruckte deutsche Übersetzung: «Und du frage nach mir - ich werde auch nach dir fragen». Krapfs Abschrift scheint in der Bedeutung um wenige Grade unexakter als das Original, da Tewodros nicht persönlich mit Gobat in Kontakt war, sondern über Mittelsmänner, und sie vereinfacht ihre Aussage: «Ich werde dich besuchen» (lit. für «Ich werde nachfragen, wie es Dir geht»), wobei dies, wie auch in anderen Fällen, keine wesentlichen Veränderungen im Sinn bringt. 


\section{SUMMARY}

The article presents a number of $19^{\text {th }}$-cent. letters related to the Protestant missionary circles in Ethiopia of the time of King Tewodros II (r. 1855-1868). Most of the letters were penned by Ethiopian converts; they were printed in Europe in a newsletter of the St. Chrischona-Pilgermission, and addressed to other missionaries. Amharic originals are missing for most of these peculiar documents; however, they extend the documentary basis of the history the Ethiopian Protestant movement and allow to make valuable insights into the mentality and way of thinking of the first Ethiopian Protestants. Of special interest is another copy of one well-known letter of Tewodros II, addressed to Samuel Gobat, which was prepared for J. L. Krapf and remained in posession of M. Flad. 